\title{
Japanese Interest Rate Forecast Considering the Linkage of Global Markets Using Machine Learning Methods
}

\author{
Yoshiyuki Suimon *, Hiroki Sakaji ${ }^{\dagger}$, \\ Kiyoshi Izumi $^{\dagger}$, Takashi Shimada ${ }^{\dagger}$, Hiroyasu Matsushima ${ }^{\dagger}$
}

\begin{abstract}
In recent years, overseas financial system crises (e.g., Lehman shock and European debt crisis) and the effects of monetary policy changes by US and European central banks exerted major influence on the Japanese interest rates market. In this research, we developed a forecasting model of Japanese interest rate based on a variety of machine learning methods, by considering the information obtained from overseas rates markets and currency markets. Finally, we confirmed that the prediction accuracy of Japanese long-term interest rate improved by using the US interest rates data in addition to the Japanese interest rates data for machine learning. Furthermore, we confirmed that the prediction accuracy increased by using US and Japanese rates markets data in recent years, particularly after 2006. This result suggests that information of overseas interest rates can be used to forecast Japanese rates market nowadays.

Keywords: Interest Rate Forecast, Japanese Government Bond, Machine Learning, Neural Network, US Treasury Bond, Yield Curve
\end{abstract}

\section{Introduction}

Long-term interest rate is a representative indicator that reflects the degree of economic activities and is generally defined as a long-term (10 year) government bond yield. In the financial market, government bond's price is dependent on market participants. The market price determines the macroeconomic fundamentals and is also influenced by various supply and demand factors in the market. In addition, fluctuations of overseas interest rates, which are caused by overseas financial system events (e.g., the Lehman shock and the European debt crisis) and the effects of monetary policy changes by US and European central banks, often affect the Japanese interest rates market. Mechanisms in which the interest rate fluctuations in overseas markets shift directly to Japanese in-

\footnotetext{
* Department of Systems Innovations, School of Engineering, The University of Tokyo, Tokyo, Japan Financial and Economic Research Center, Nomura Securities Co., Ltd., Tokyo, Japan

$\dagger$ Department of Systems Innovations, School of Engineering, The University of Tokyo, Tokyo, Japan
} 
terest rates market through global financial transactions, such as derivative contracts and various interest rate arbitrage transactions, also exist.

In this research, we focused on the influence of fluctuations in overseas rates market and currency market to Japanese rates market and verified the usefulness of US interest rates data and Dollar-Yen exchange rate data, in predicting the Japanese long-term interest rate. We developed the prediction models of Japanese interest rate changes based on the results by using various machine learning methods (e.g., support vector machine (SVM), decision tree (DT), random forest (RF), logistic regression, k-nearest neighbor, multilayer perceptron (MLP), recurrent neural network (RNN), and long short-term memory (LSTM)). Then, we showed the improvement of the prediction accuracy for Japanese long-term interest rate by using the US interest rates data in addition to the Japanese interest rates data for the machine learning based model building. We assumed that the influence of the US market to the Japanese market increased recently because of the current globalization of the financial system. Hence, we verified the influence of US market data to the Japanese rate forecast increase in recent years by simulating the interest rate prediction based on the machine learning models that we proposed.

\section{Long-Term Interest Rate and Yield Curve}

\subsection{Japanese and US long-term interest rate}

Long-term interest rate (long-term government bond yield) is a representative indicator of macroeconomic fundamentals. Thus, while incorporating changes in various macroeconomic environments, the price of long-term government bonds traded in the market and long-term interest rates also changes daily.

Figure 1 shows the actual trend of long-term interest rates in Japan (10 year government bond yield). The figure also illustrates other maturities' interest rates of Japanese government bonds (JGB) and US Treasury bonds. On the basis of the figure, the changes in the interest rate level in Japan and the US link to some extent, and in recent years, the interest rate level is declining.

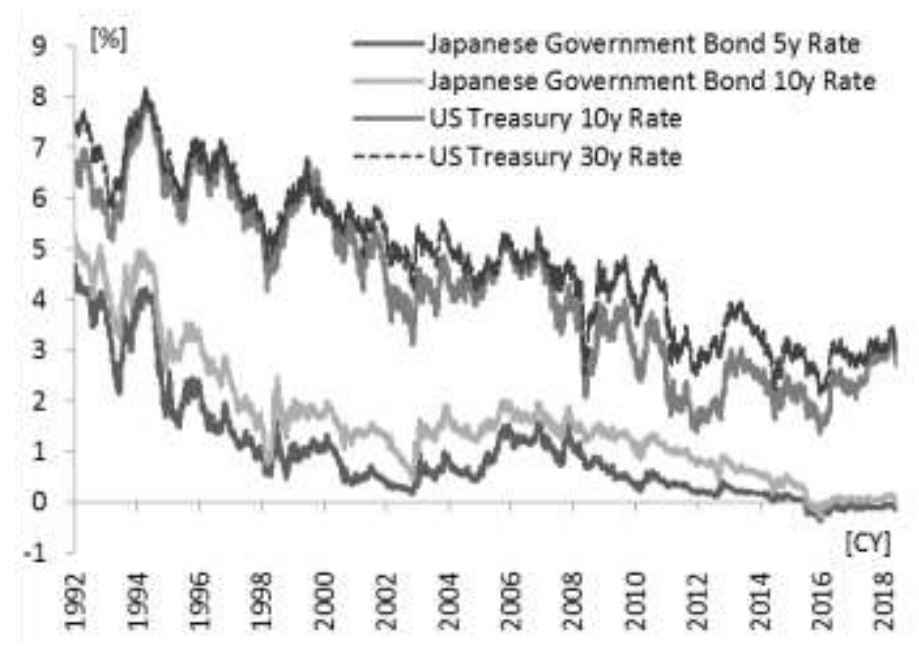

Figure 1: Historical data of JGB and US Treasury rates 


\subsection{Term structure model of the yield curve}

The changes in Japanese and US long-term interest rates are as shown in Figure 1. In Japan, 2, 5, 10, 20, 30, and 40 years of government bonds have been issued, and there are market interest rates of each maturity (term). The curve that connects these various term interest rates is called yield curve (Figure 2).

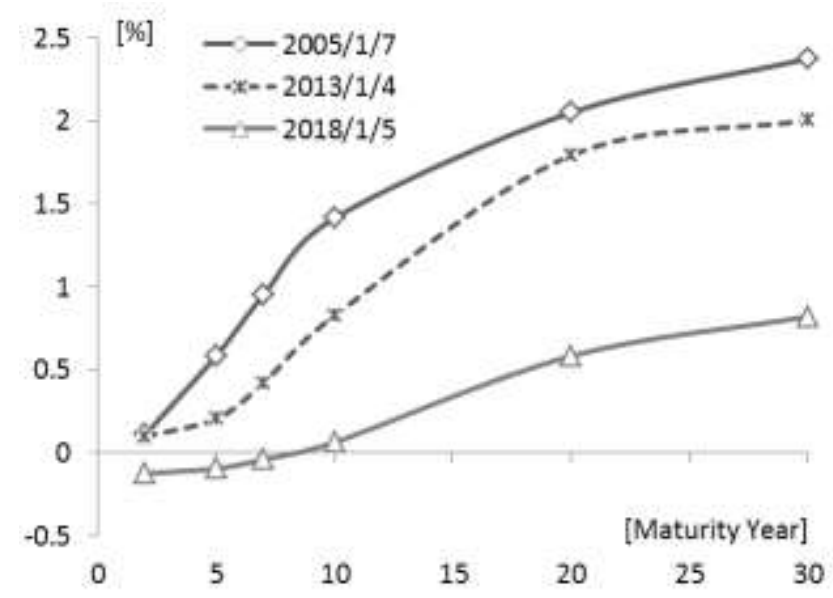

Figure 2: JGB yield curve

The interest rate level of the yield curve of government bonds is basically determined by the influence of the macroeconomic environment and monetary policy. However, depending on the term (maturity), the characteristics of the market participants who actually trade the government bonds and the purpose of the trading vary. Consequently, the fluctuation characteristics of the interest rate also differ depending on the term.

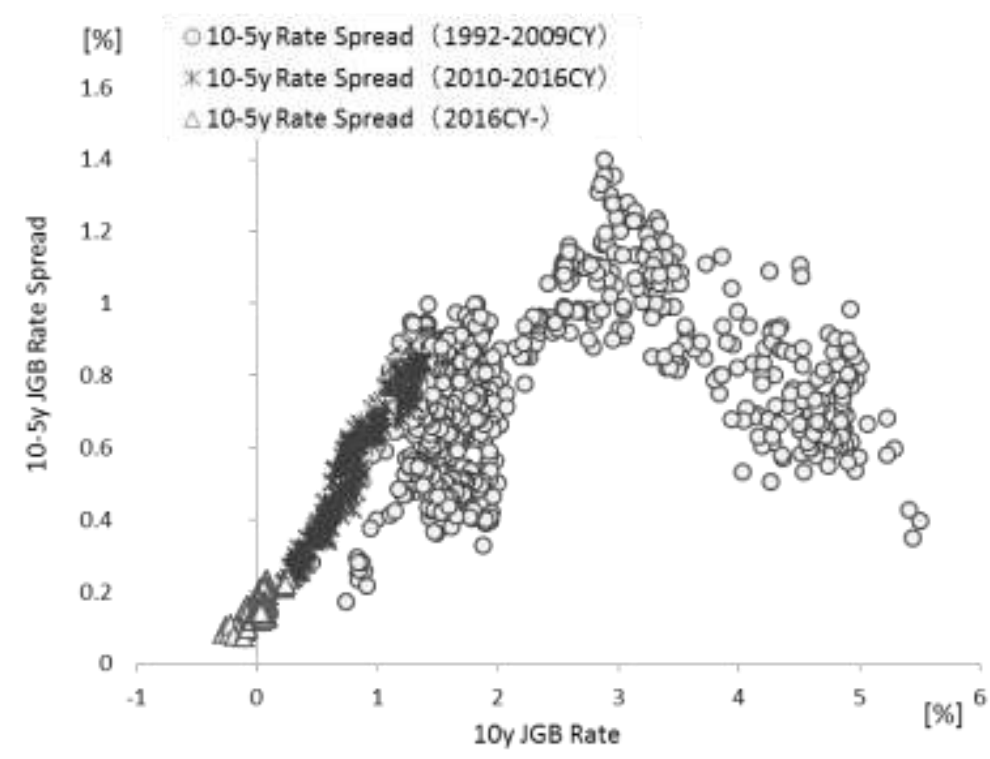

Figure 3: 10-5 year JGB rate spread and 10 year rate level 
For example, in the Japanese market, short-term interest rates are generally poorly variable because they are directly influenced by central bank's interest rate control target. In addition, medium- to long-term interest rates fluctuate while incorporating changes in the macroeconomic environment where market price formation mechanism works. When the interest rate spread between the terms widens, the demand for high interest rate government bonds increases, resulting in tightening pressure on the interest rate differential. Moreover, the fluctuation characteristics of the yield curve vary depending on the interest rate level. Figure 3 shows the relationship between the 10-5 year interest rate spread (i.e., 10- and 5-year interest rates) and 10 year interest rate level. According to this relationship, when the level of the 10 year interest rate rises to a certain level, the 10-5 year interest rate spread tends to widen. However, after that, the level of the 10 year interest rate rises, and the 10-5 year interest rate spread tends to become narrow this time.

In this way, fluctuations of the government bond yield curve are caused by investors' behavior, which depends on the relative value and absolute level between the terms, and the existence of an arbitrage transaction focusing on the difference between the interest rates of different terms. That is, the fluctuations in the yield curve are caused by endogenous factors based on the shape of the yield curve itself.

The characteristics of the JGB interest rates' fluctuations also differ depending on the maturity year (term). Thus, we use principal component analysis (PCA) on the weekly change of the JGB yield curve (weekly change of JGB yields of maturities of 2, 5, 7, 10, 15,20 years) in order to confirm the characteristics of the each maturity' yield. The sample period of PCA is from 1992 to 2018. Figure 4 shows the contribution of each PCA factors. According to this, we can see that the fluctuation of yield curve over $95 \%$ can be explained by the 1 st to 3rd PCA factor.

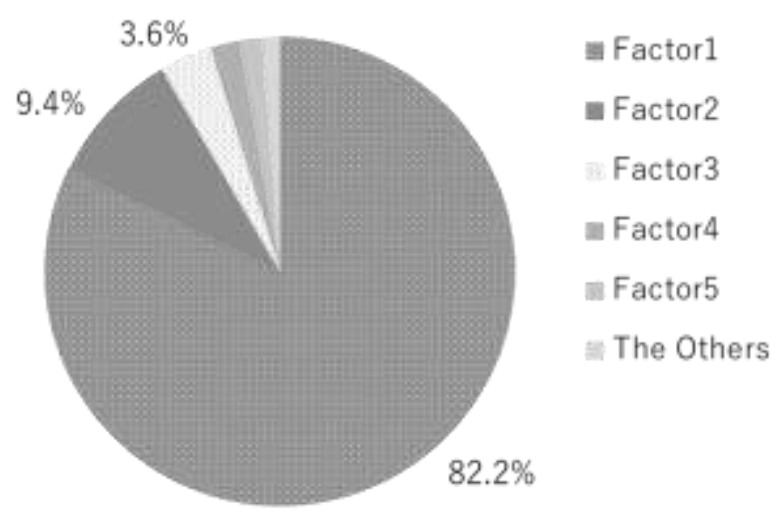

Figure 4: Contribution of PCA Factors

Furthermore, Figure 5 shows the shape of the 1st to 3rd PCA factors' eigenvector. Based on this figure, the meaning of the each factor can be interpreted as the level, slope and curvature. 


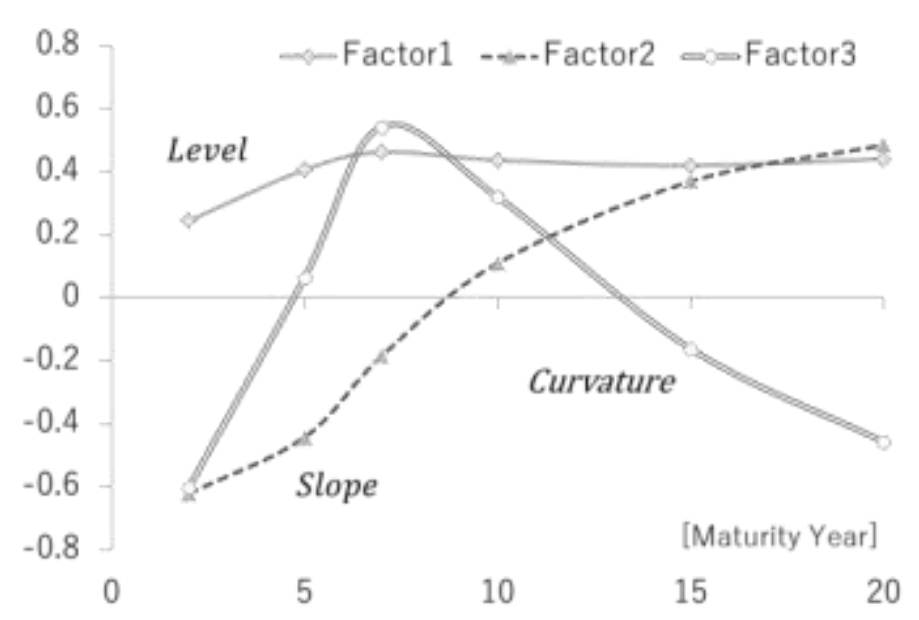

Figure 5: Eigen vector of PCA Factor 1-3

\subsection{Building of yield curve model}

In this research, when modeling the change of the yield curve term structure, we would set the level, slope, and curvature information by using the data of the interest rate changes in 5, 10, and 20 years. By using the information on interest rate changes in the three terms, apart from the information regarding the change of each level, acquiring information on the changes of the slope and curvature is also possible. For example, the difference between 5-10 and 10-20 year spread indicates the yield curve curvature, whereas 5-20 year spread demonstrates the entire yield curve slope. By modeling the interest rates term structure based on the information of three points' interest rate changes by using this technique, we will construct models that determines the fluctuation characteristics of long-term interest rate generated by endogenous factor, that is, the shape of the yield curve itself.

\section{Link Between the US and Japan Yield Curve}

\subsection{Japanese market participants recognize overseas rates}

As mentioned above, the long-term interest rate is also affected by the relative relationship with other terms, but it is also expected to be affected by foreign markets. As shown in Figure 1, the interest rates of Japan and the US have some degree of interoperability. Indeed, to what extent do participants in the Japanese government bond market care about overseas market movements? Questionnaire survey "QUICK Monthly Market Survey (Bond)" that "QUICK company" conducts monthly on Japanese bond market participants can be a reference to consider this point.

One question in the questionnaire is "What is the most noteworthy bond price fluctuation factor?" On the basis of the 1996 questionnaire survey (Figure 6), among the participants in the Japanese bond market, the proportion that responded "Economy," followed by "Short-term Rates, Monetary Policy," was high. However, as of 2018, the proportion that responded "Foreign Interest Rates" instead of "Economy" is increasing. 


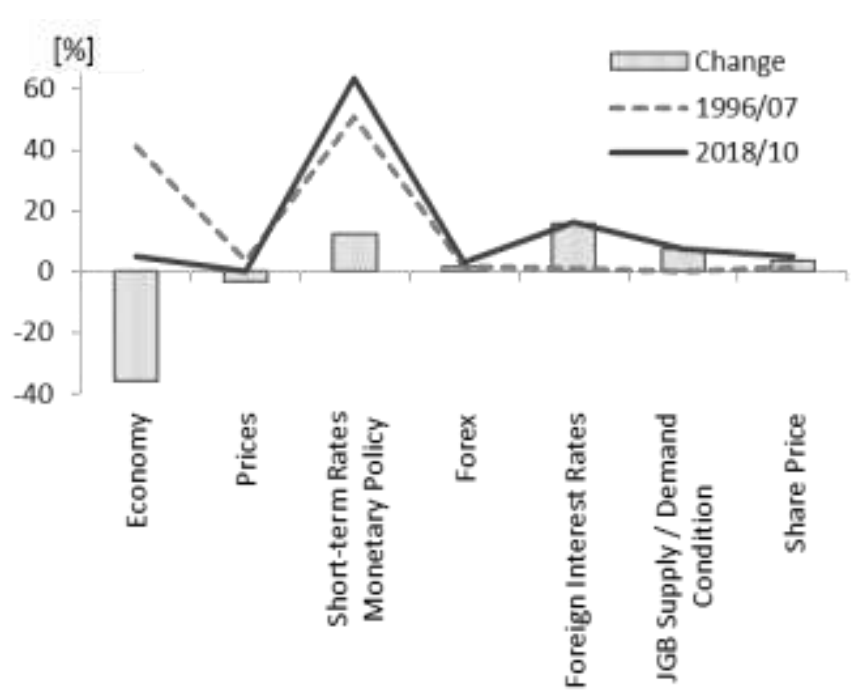

Figure 6: Causes of JGB market movements according to Quick Survey

Figure 7 shows the percentage trend of "Economy" and "Foreign Interest Rates" responses in the questionnaire survey. As shown in the figure, the ratio of "Foreign Interest Rates" is evidently increasing since 2006. Meanwhile, the response rate of "Economy" has a downward trend.

Indeed, various financial fluctuations in overseas financial markets, which are caused by overseas financial system events (e.g., the Lehman shock in 2008 and the European debt crisis in 2010) and the effects of changes in monetary policy at the central banks of Europe and the US, had a remarkable influence on price formation of Japanese interest rates market. Therefore, a mechanism in which the interest rate fluctuations in overseas markets are directly transferred to Japanese interest rates market through global financial transactions, such as derivative contracts and various interest rate arbitrage strategies, exists. As a result of the global financial system development, Japanese market participants concern about not only fundamental factors (e.g., Japan's economic condition) but also the influence of interest rate fluctuations in overseas markets. Thus, we assume that overseas markets influence price formation in Japanese interest rates market.

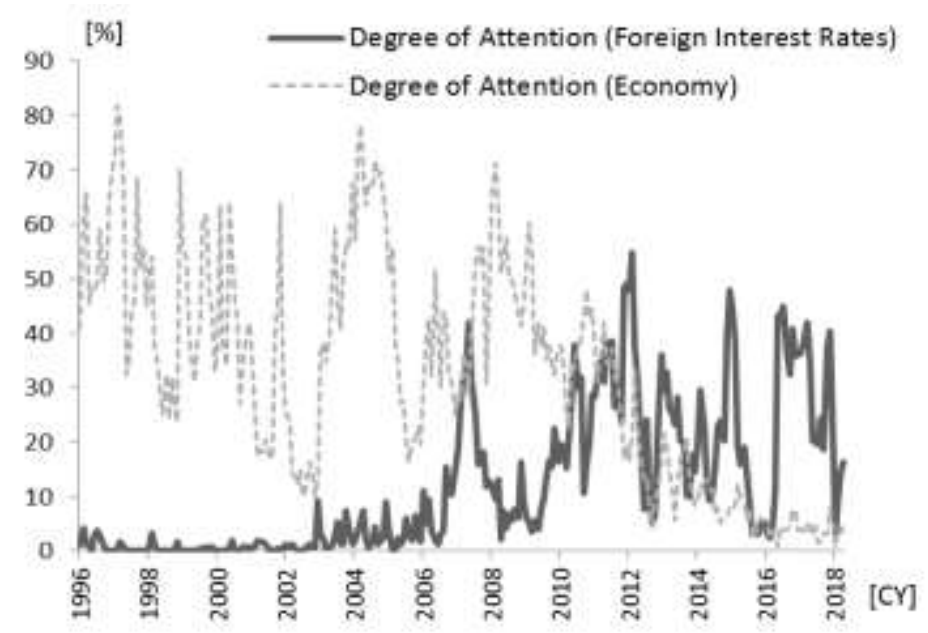

Figure 7: Input and label data for the modeling (only the Japanese data) 


\subsection{Linkage of US and Japanese interest rates}

In this section, on the basis of the questionnaire results of market participants, we briefly verified how the yield curves of Japan and the US actually link. Specifically, we focus on the correlation between weekly changes in interest rates in Japan and overseas markets.

The value indicated by the arrow in Figure 8 is the correlation coefficient between "Weekly changes in 10 year interest rate of Japanese government bond" and "Weekly changes in 2 year interest rate of US Treasury bond" in "2000". We use the Japanese government bonds' interest rate data of 2, 5, 10, 20 years, US government bonds' interest rate data of 2, 5, 10, 30 years, and German government bonds' interest rate data of 2, 5, 10, 20 years. Figure 8 shows the correlation matrix of the weekly changes of these global interest rates. According to Figure 8, in 2000, the correlation between interest rates for different maturities in the Japanese market is high. Similarly, the correlation between interest rates for different maturities in the US and European markets is high. However, the correlation between interest rates in the Japanese market and the US (European) markets is relatively low.

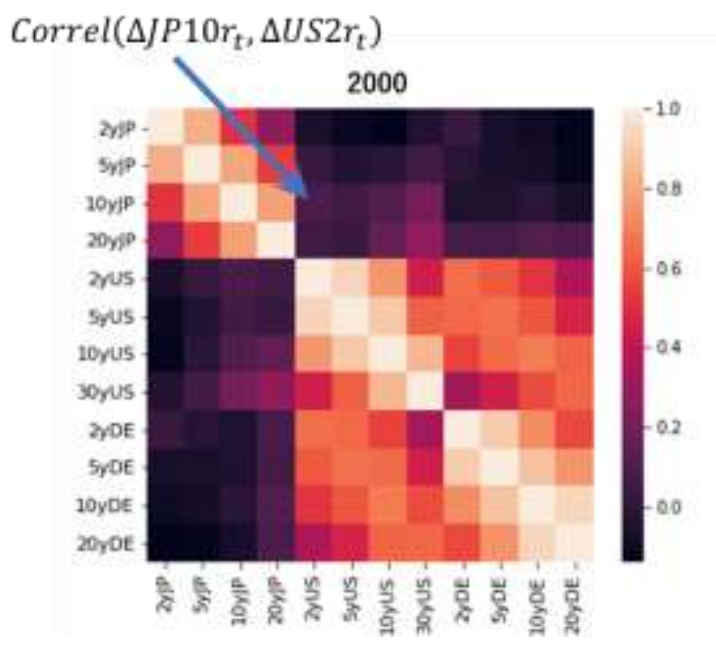

Figure 8: Correlation Matrix of Global Interest rates in 2000

In addition, the following Figure 9 and 10 show the correlation matrices for other years. According to these results, the correlation matrix before 2006 shown in Figure 9 shows that the correlation between interest rates for different maturities in the Japanese market is high and the correlation between interest rates for different maturities in the European and American markets is also high. However. The correlation between interest rates in the Japanese and the US (European) markets is relatively low. On the other hand, since 2006, as shown in Figure 10, the correlation between Japanese and European and US market interest rates has increased compared to before.

Figures 9 and 10 provide a visual indication of the recent increase in the linkages between global interest rate markets. In the following, we would like to mathematically show the similarity of recent correlation matrices by using cluster analysis. In Figure 11, for the global interest rates' correlation matrices from 2000 to 2018, similar correlation matrices were grouped by the Ward method, which is a hierarchical clustering method. 
In this analysis, the Euclidean distance was used as the distance indicating the similarity. As a result, groups have roughly split in recent years, especially around the 2008 Lehman Shock. These analysis results support the idea that the usefulness of information on global markets is increasing even for forecasting the Japanese interest rate market especially in recent years. In this study, we analyzed the characteristics of the interest rate market, and [1] analyzed the characteristics of the stock market and its changes based on correlation and cluster analysis.
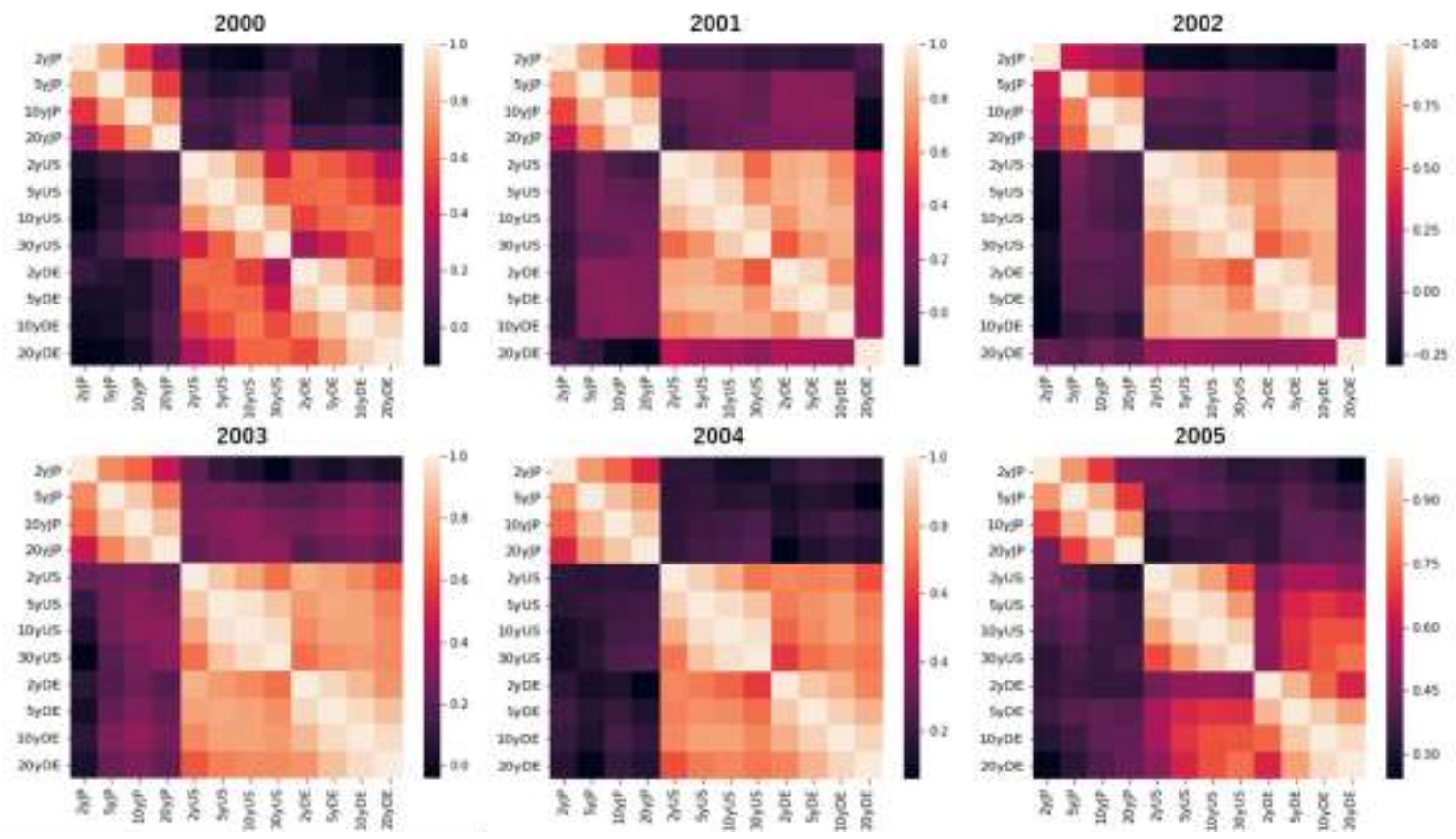

Figure 9: Correlation Matrix of Global Interest rates from 2000 to 2005
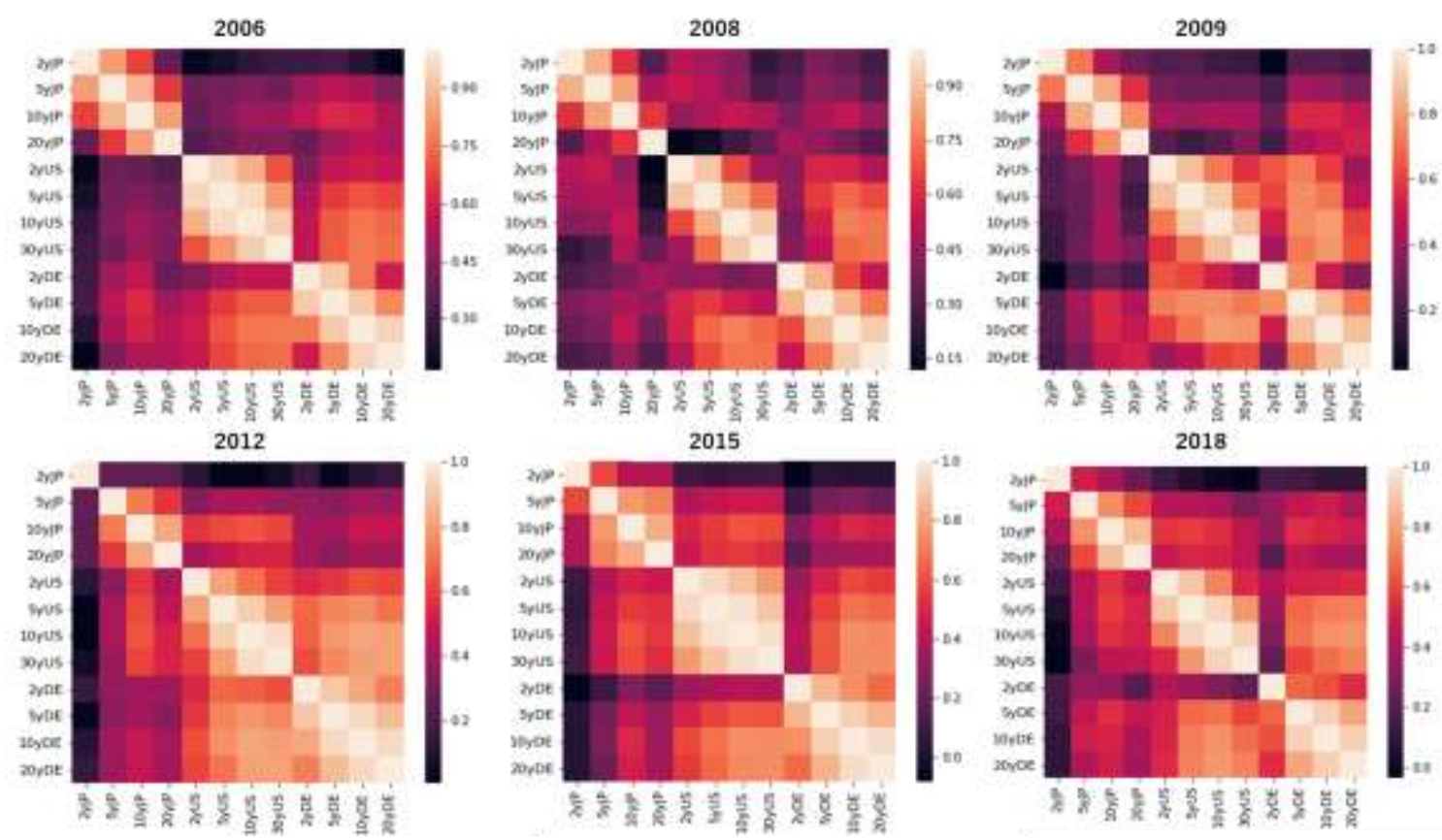

Figure 10: Correlation Matrix of Global Interest rates from 2006 to 2018 


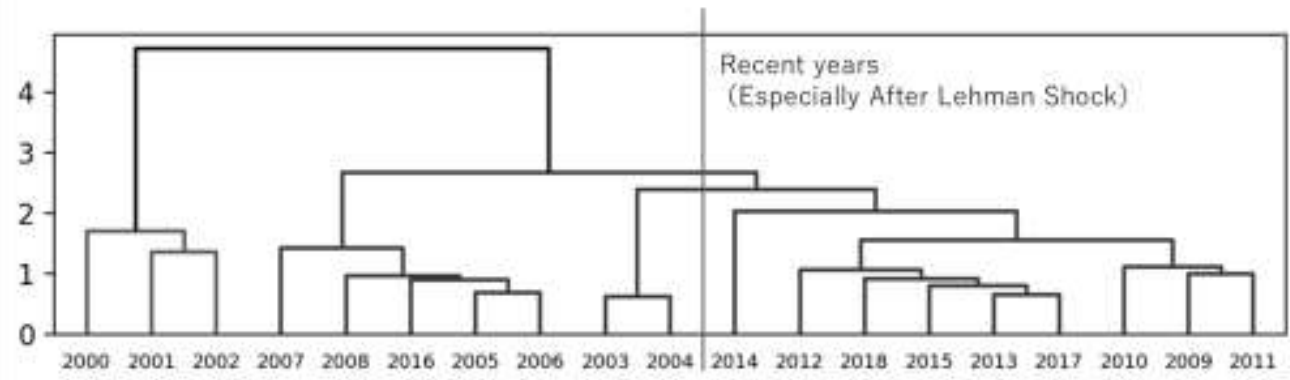

Figure 11: Cluster Analysis of Global Interest rates' Correlation Matrix

\section{Development of Machine Learning Model and Long-Term Interest Rate Forecasting}

\subsection{Feature engineering}

In this section, based on the above points, we will predict the Japanese long-term interest rate through machine learning models. In the previous study [3], the Japanese long-term interest rate was predicted using the interest rate term structure model based on machine learning method. In this research, we predicted the Japanese long-term interest rates based on the models that use only the Japanese interest rate data for the machine learning. In addition, we envisioned the Japanese long-term interest rates based on the models that use the Japanese and US interest rate data for learning. Thus, we verified the improvement of the prediction accuracy by using additional US data for the machine learning.

First, as mentioned in Section 2.1, we developed the interest rate term structure model by using only the Japanese interest rate data of 5, 10, and 20 years. In establishing the term structure model based on machine learning, we used the daily interest rate changes over the past 3 days at each term $(5,10$, and 20 years) as the input data and the change in interest rate over the following day of each term as the label data. The relationship between the input and label data used for learning is shown in Figure 12. In this model, we can predict the changes in interest rates in the subsequent day of each term based on 3 day interest rate changes of 5,10 , and 20 years.

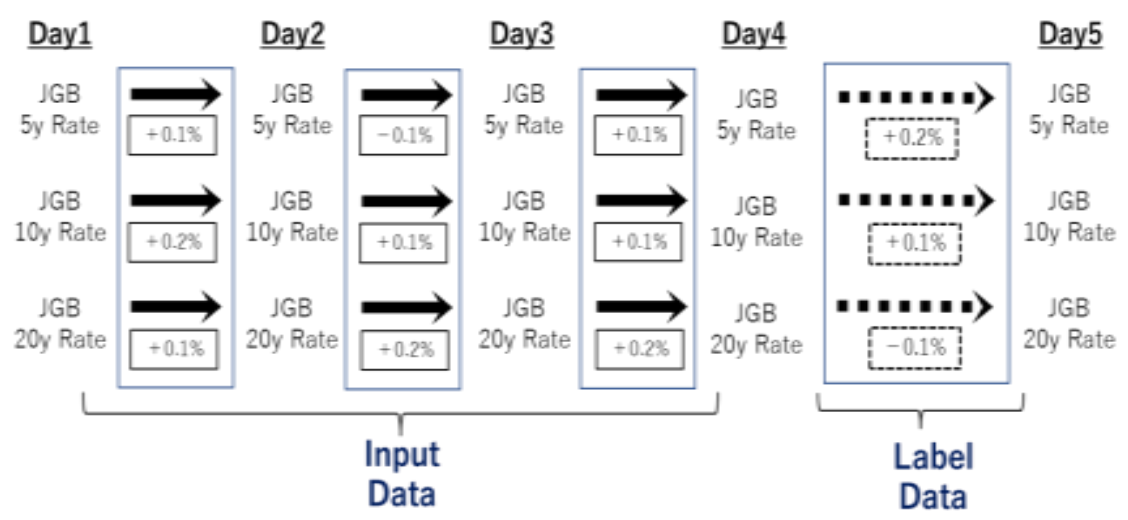

Figure 12: Input and label data for the modeling (only the Japanese data) 
Subsequently, we developed a model that uses not only interest rates data of the Japanese market but also that of the US market for the machine learning. Specifically, we used the US interest rate changes of 5, 10, and 30 years in the past 3 days in addition to the changes in Japanese interest rates of 5, 10, and 20 years in the past 3 days as the input data. Moreover, we utilized the data of the Japanese interest rate changes of 5, 10, and 20 years in the following day as the label data. The relationship between these input and label data used for learning is illustrated in Figure 13.

The point is the difference between Japan and US time zones. The closing price data of the US market can be obtained approximately half a day after the Japanese market closed on that day. Because the US time trading of Day4 is concluded before the Japanese time Day5 market opens, the trading hours of both markets do not overlap. On the basis of this point, we will aim to improve the prediction accuracy of the Japanese interest rate change over the subsequent day by using the data of the US interest rates of 5, 10 , and 30 years in addition to the Japanese interest rates of 5, 10, and 20 years as the input data.

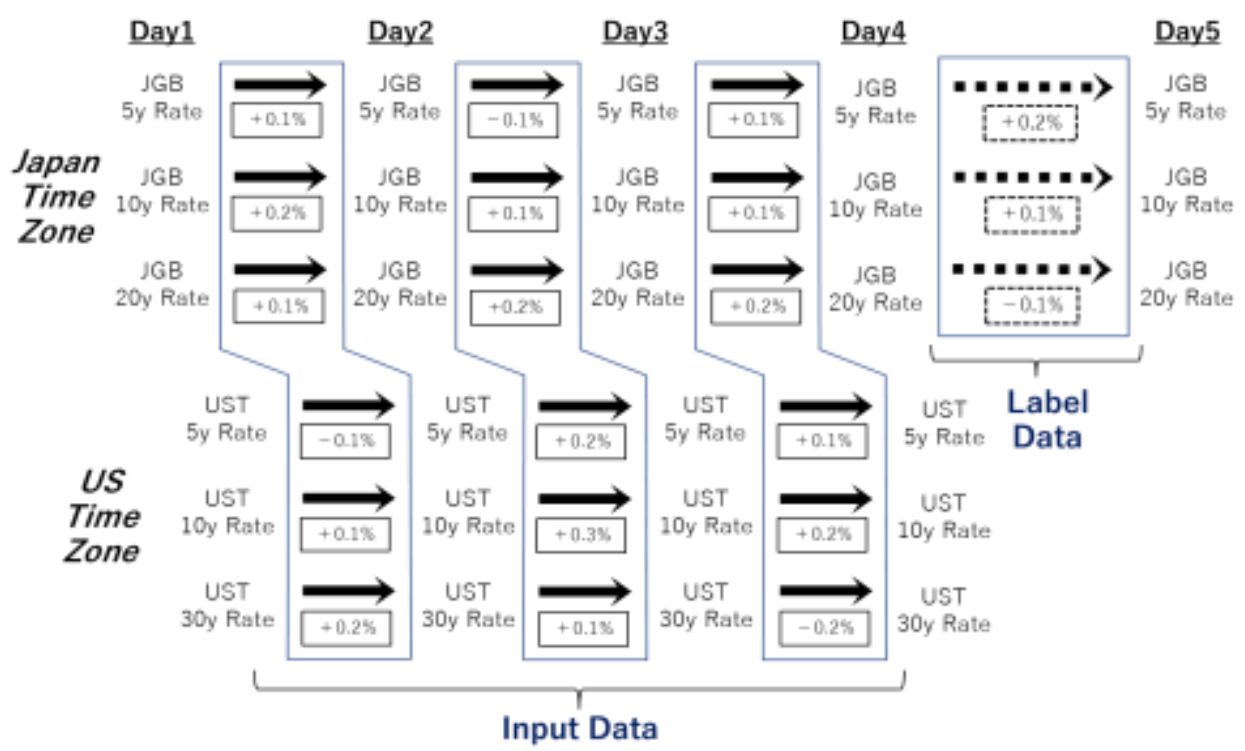

Figure 13: Input and label data for the modeling (including the US data)

Furthermore, we would like to use the information of the exchange rate. The Dollar-Yen rate, which is the currency rate between the US and Japan, is determined by the relative relationship between the US and Japan interest rates. This relationship is called interest rate parity, and as shown in Figure 14, if the current exchange rate is Spot FX, and the 5-year interest rates for Japan and the US are $r_{J P}$ and $r_{U S}$, then the 5-year forward exchange rate is as follow.

$$
\text { 5Y Forward FX }=\text { Spot } F X \times \frac{\left(1+r_{i p}\right)^{5}}{\left(1+r_{i S}\right)^{5}}
$$

Thus, there is an arbitrage between the forward exchange rate and the interest rates of the two countries. Also, although the spot rate and the forward rate are different depending on the forward period, the changes in the rates themselves are almost similar. Based on 
this point, in addition to interest rate data from the US and Japan markets, we also use data for Dollar-Yen rate daily changes (17:00 US time before the start of the Japanese market) as the input data for the model building.

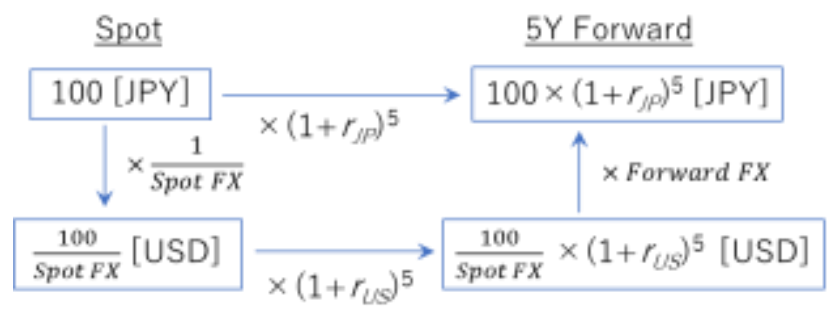

Figure 14: Interest Rate Parity

\subsection{Building machine learning-based yield curve model}

In this research, we will implement the models based on machine learning methods by using the daily data of Japanese and US government bond yields from August 1992 to September 2018. We implement various machine learning methods, such as SVM, DT, RF, logistic regression, k-nearest neighbor, MLP, RNN, and LSTM. The interest rates data of Japanese government bonds are published by the Ministry of Finance Japan, and the rates data of the US Treasury bonds are published by the Board of Governors of the Federal Reserve System.

In the machine learning of the models based on SVM, DT, RF, logistic regression, and k-nearest neighbor, we set the information on changes of the market data over the past 3 days ("Data1: Japanese 5, 10, 20 years interest rates", "Data2: Japanese 5, 10, 20 years interest rates and US 5, 10, 30 years interest rates", "Data3: Japanese 5, 10, 20 years interest rates and US 5, 10, 30 years interest rates and Dollar-Yen exchange rate") as the input data. We also set the binary value whether the Japanese 10 year interest rate rises or falls the following day as the label data for the machine learning.

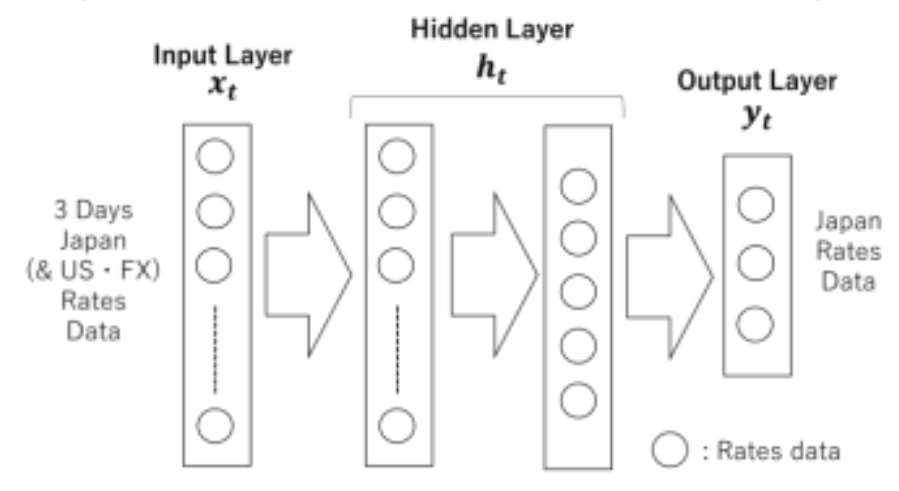

Figure 15: Neural network structure for the MLP

In the machine learning of the models based on MLP, we set the information on changes in interest rates and currency rate over the past 3 days ("Data1: Japanese 5, 10, 20 years 
interest rates", "Data2: Japanese 5, 10, 20 years interest rates and US 5, 10, 30 years interest rates", "Data3: Japanese 5, 10, 20 years interest rates and US 5, 10, 30 years interest rates and Dollar-Yen exchange rate") as the input data. We also set the changes of the Japanese 10 year interest rate over the following day as the label data for the machine learning. When using the US market data, the vector of the input data becomes six dimensional (i.e., the interest rate change of 3 periods $\times 2$ countries), and when using the currency market data, the vector of the input data becomes seven dimensional (i.e., the interest rate change of 3 periods $\times 2$ countries and the currency rate), whereas the vector of the output data corresponds to the Japanese interest rate changes of 5, 10, and 20 years, and this vector is three dimensional.

Furthermore, when constructing the machine learning models based on RNN and LSTM, we set the three-dimensional vector of the Japanese interest rate changes of 5, 10 , and 20 years from $t-1$ to $t$ days as the input data $x_{t}$. We also use the US interest rate changes of 5, 10, and 30 years (and Dollar-Yen exchange rate) in addition to the Japanese data as the input data of machine learning for comparison.

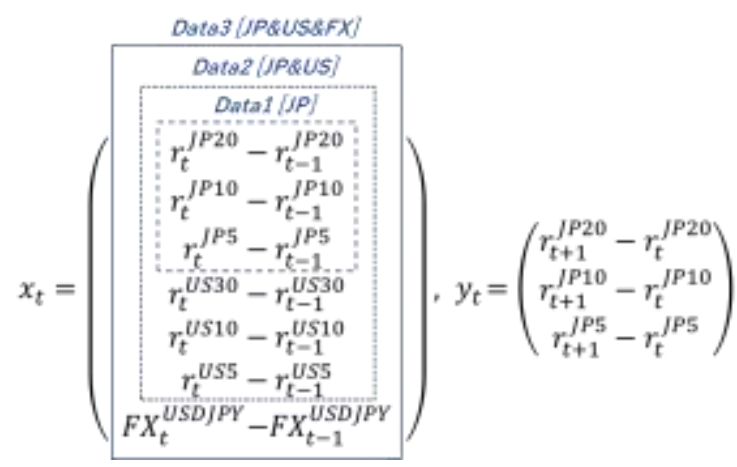

Then, we use the interest rate changes, $x_{t}, x_{t-1}$, and $x_{t-2}$ in the past 3 days as the input data for the recurrent network, whereas the vector $y_{t}$ that corresponds to the Japanese interest rate changes of 5,10 , and 20 years from day $t$ to day $t+1$ is set as the label data for the machine learning.

\section{Evaluation}

\subsection{Prediction accuracy of the models}

In this section, we present the verification results of the Japanese long-term interest rate (10 year government bond yield) forecast based on the abovementioned various learning models. According to the results of the QUICK questionnaire, we divide the sample period into periods 1992-2005 and 2006-2018 and verified the performance of the machine learning models. For the verification, the model was learned using $80 \%$ of the randomly extracted data for each sample period as the training data, and the remaining $20 \%$ was used as the test data. Moreover, we calculated the prediction accuracy of the learned models based on the test data. 
Table 1: STRUCTURE OF EACH MACHINE LEARNING MODELS

\begin{tabular}{|c|c|c|}
\hline Name & Model & Model structure \\
\hline Same & Same as Yesterday & $\begin{array}{l}\text { JP: Same as yesterday's JP direction } \\
\text { JP\&US: Same as yesterday's US direction } \\
\text { JP\&US\&FX: Same as yesterday's US direction }\end{array}$ \\
\hline $\operatorname{LinRe}$ & Linear Regression & \\
\hline LogiRe & Logistic Regression & Regularization parameter $\mathrm{C}=1$ \\
\hline LinSVM & Support Vector Machine & $\begin{array}{l}\text { Linear SVM } \\
\text { Penalty parameter } C=1\end{array}$ \\
\hline SVM & Support Vector Machine & $\begin{array}{l}\text { Nonlinear SVM Using Gaussian Kernel } \\
\text { Penalty parameter } C=1\end{array}$ \\
\hline DT & Decision Tree Classifier & \\
\hline RF & Random Forest Classifier & \\
\hline kNei & k-Neighbors Classifier & Number of neighbors: 5 \\
\hline MLP1 & Multilayer perceptron & $\begin{array}{l}\text { Activation function: Hyperbolic tangent } \\
\text { Number of nodes for each layers } \\
\text { JP: } 9-9-3 \text {, JP\&US: } 18-18-3 \\
\text { JP\&US\&FX: } 21-21-3\end{array}$ \\
\hline MLP2 & Multilayer perceptron & $\begin{array}{l}\text { Activation function: Hyperbolic tangent } \\
\text { Number of nodes for each layers } \\
\text { JP: } 9-5-3 \text {, JP\&US: } 18-10-3 \\
\text { JP\&US\&FX: } 21-10-3\end{array}$ \\
\hline MLP3 & Multilayer perceptron & $\begin{array}{l}\text { Activation function: Hyperbolic tangent } \\
\text { Number of nodes for each layers } \\
\text { JP: } 9-9-5-3 \text {, JP\&US: } 18-18-10-3 \\
\text { JP\&US\&FX: } 21-21-10-3\end{array}$ \\
\hline MLP4 & Multilayer perceptron & $\begin{array}{l}\text { Activation function: Hyperbolic tangent } \\
\text { Number of nodes for each layers } \\
\text { JP: } 9-5-5-3 \text {, JP\&US: } 18-10-10-3 \\
\text { JP\&US\&FX: } 21-10-10-3\end{array}$ \\
\hline RNN1 & Recurrent neural network & $\begin{array}{l}\text { Activation function: Hyperbolic tangent } \\
\text { Number of nodes of hidden layer: } 100\end{array}$ \\
\hline RNN2 & Recurrent neural network & $\begin{array}{l}\text { Activation function: Hyperbolic tangent } \\
\text { Number of nodes of hidden layer: } 50\end{array}$ \\
\hline LSTM1 & Long short-term memory & $\begin{array}{l}\text { Activation function: Hyperbolic tangent } \\
\text { Recurrent Activation function: Sigmoid } \\
\text { Number of LSTM blocks: } 100\end{array}$ \\
\hline LSTM2 & Long short-term memory & $\begin{array}{l}\text { Activation function: Hyperbolic tangent } \\
\text { Recurrent Activation function: Sigmoid } \\
\text { Number of LSTM blocks: } 50\end{array}$ \\
\hline
\end{tabular}

Specifically, in the verification of the prediction models based on SVM, DT, RF, logistic regression, and k-nearest neighbor, the prediction accuracy of the test data was calculated by comparing the direction of the forecasted 10 year interest rate of the following 
day with the actual direction. The forecasted 10 year interest rate was predicted using the learned model. In the verification of the prediction models based on MLP, RNN, and LSTM for the test data, we compared the direction based on the forecasted 10 year interest rate of the following day with the actual direction. In addition, the forecasted 10 year interest rate was predicted using the learned model. For the prediction performance comparison between the model that used the only Japanese market data (Data1) for learning and model that use Japanese and US data (Data2) and model that use Japanese and US rates data and the currency data (Data3), the period of the training and test data is common for all models. We indicate the structure of each machine learning models in Table 1.

\subsection{Discussion}

On the basis of various models that we constructed, the accuracy rate for the following day's direction prediction of the rise/decline of the Japanese long-term interest rate is shown in Figure 16. The figure shows the accuracy rate of the models that used only the Japanese rates data for the machine learning ("Data1") and the accuracy rate of the models that used the US and Japanese rates data for the machine learning ("Data2") and the accuracy rate of the models that used the US and Japanese rates and Dollar-Yen exchange rate data for the machine learning ("Data3"). Figure 16 shows the average accuracy rate based on four types of test data for each period before and after 2006. According to these results, when the US interest rates data are used for the prediction model, significant improvements can be confirmed in the prediction accuracy of the Japanese long-term interest rate particularly after 2006.

Although there are some differences in the prediction accuracy depending on the prediction models, in this case, the prediction accuracy rate of the complicated model such as LSTM and RNN is similar to the rate of relatively simple model including linear model. For example, regarding the neural network models, the prediction accuracy did not change significantly even when the number of hidden layers and the number of nodes were increased. Based on these results, in this topic, we confirmed that the prediction accuracy is greatly improved by the setting of the feature quantity rather than by making the model complicated especially after 2006.

As we mentioned, in the period after 2006, the prediction accuracy improvement by using the US interest rate data for the machine learning is remarkable, regardless of which learning algorithm is used. On the other hand, in the case of using exchange rate data in addition to US interest rate for the machine learning (Data 3), the degree of improvement in prediction accuracy was limited. This suggests that the market pricing based on interest rate parity already works in the US time zone. 


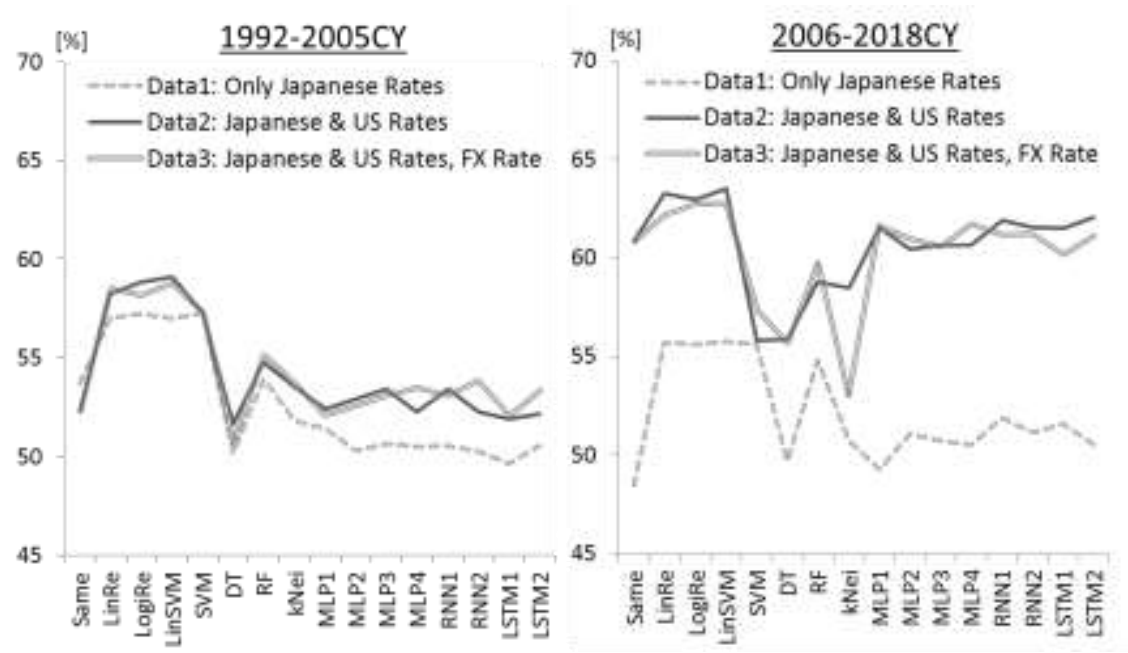

Figure 16: Accuracy for the long-term rate prediction by using the models

These results indicate that the information of the US rates market become a useful information for predicting the Japanese long-term interest rates in recent years. This is consistent with the result of the correlation analysis between Japanese and overseas markets in section 3.2, and the result of the market participants' surveys regarding the affection to the Japanese market by the overseas markets' movements in section 3.1.

Furthermore, in the actual financial markets, there are mechanisms in which the interest rate fluctuations in overseas markets are directly transferred to Japanese interest rates market through global financial transactions, such as derivative contracts and various interest rate arbitrage strategies. Especially, as a result of the global financial system development, Japanese market participants much care about the influence of interest rate fluctuations in overseas markets as we showed in section 3.1. Thus, we see that the overseas markets influence the Japanese interest rates market in recent years.

\section{Related Works}

In this research, we modeled the change of the interest rate term structure of Japanese and US government bond markets by using machine learning methods and predicted the change in the Japanese long-term interest rate based on the models. Similar to a prior study related to this research, [6] simulated the US yield curve by using the NelsonSiegel model [2] and predicted the additional changes of the three factors of the NelsonSiegel model by using the AR (1) model. Reisman and Zohar [7] extracted three principal component factors by using the principal component analysis (PCA), simulated the time series of each factor, and predicted the yield curve changes based on the time series model factors. In addition, because these studies used the PCA, [8] and [9] conducted the PCA on various macro indexes and predicted the interest rates based on the established macro-based PCA factors.

Furthermore, [3] proposed the yield curve models based on machine learning methods. 
Suimon [3] expressed the interest rates term structure by focusing on the relative relationship of the three periods (i.e., 5, 10, and 20 year interest rates) of the yield curve instead of Nelson-Siegel's three factors. He also modeled the yield curve based on machine learning methods, such as LSTM, and forecasted the long-term interest rate by using the models. Studies that use machine learning methods for financial markets have been conducted particularly in the stock markets' forecast. For example, a number of research on stock price prediction by using neural networks have been reported [10]. In addition, [11] demonstrated the utility of neural network model for the Canadian stock market forecast with various accounting ratios as the input data for the machine learning. Krauss et al. [12] predicted the next day's US stock market by using the combination of three different machine learning methods (i.e., deep neural networks, gradient-boosted trees, and RF) and reported that the prediction accuracy of the combined method exceeds each method's prediction accuracy. Regarding the deep learning-based research for financial markets aside from the stock market, [13] focused on commodity and foreign exchange markets.

\section{Conclusion}

In this research, we focused on the effect of the US interest rates and Dollar-Yen exchange rate changes to the Japanese market. We verified the usefulness of the US market information for predicting the Japanese interest rates market by using various machine learning methods. Specifically, we compared the prediction accuracy of the Japanese long-term interest rate based on the model that used only the Japanese interest rates market data for machine learning with the prediction accuracy based on the model that used the Japanese and US markets data for machine learning. Then, we confirmed the accuracy improvement of Japanese long-term interest rate prediction by using the US interest rates data in addition to the Japanese rates data for the machine learning of the prediction models. This tendency has remarkably improved particularly in recent years. These results are consistent with the fact that the trend of Japanese market participants to pay close attention to overseas interest rates increased since 2006, based on the questionnaire survey conducted on Japanese government bond market participants. In recent financial markets, various foreign interest rate fluctuation factors, such as overseas financial crisis and overseas central banks' monetary policy changes, can directly affect the Japanese interest rates market through various derivative contracts between global financial institutions and various interest rate arbitrage transactions. Our research showed that the information on overseas market is useful for predicting the Japanese interest rates market by using machine learning models, particularly in the modern era of global financial systems. 


\section{References}

[1] Michael C. Münnix, Takashi Shimada, Rudi Schäfer, Francois Leyvraz, Thomas H. Seligman, Thomas Guhr and H Eugene Stanley, "Identifying states of a financial market," Scientific reports, Vol.2, No.644, 2012

[2] Charles Nelson and Andrew F Siegel, "Parsimonious Modeling of Yield Curves," The Journal of Business, Vol.60, No.4, pp.473-489, 1987

[3] Yoshiyuki Suimon, "Fluctuation model of JGB yield curve using machine learning and the interest rate prediction," The Japanese Society for Artificial Intelligence, SIG-FIN, No.21, pp.46-49, 2018

[4] Sepp Hochreiter and Jürgen Schmidhuber, "Long Short-Term Memory, Neural Computation," Vol.9, No.8, pp.1735-1780, 1997

[5] Felix A. Gers, Jürgen Schmidhuber and Fred A. Cummins, "Learning to Forget: Continual Prediction with LSTM," Neural Computation, Vol.12, No.10, pp.2451-2471, 2000

[6] Francis X. Diebold and Canlin Li, "Forecasting the term structure of government bond yields," Journal of Econometrics, Vol.130, pp.337-364, 2006

[7] Haim Reisman and Gady Zohar, "Short-Term Predictability of the Term Structure," The Journal of Fixed Income, Vol.14, No.3, pp7-14, 2004

[8] Emanuel Moench, "Forecasting the yield curve in a data-rich environment: A no-arbitrage factor-augmented VAR approach," Journal of Econometrics, Vol.146, No.1, pp26-43, 2008

[9] Sydney C. Ludvigson and Serena Ng Author, "Macro Factors in Bond Risk Premia," The Review of Financial Studies, Vol.22, No.12, pp.5027-5067, 2009

[10] Sneha Soni, "Applications of ANNs in stock market prediction: a survey," International Journal of Computer Science \& Engineering Technology, Vol.2, No.3, pp.71-83, 2011

[11] Dennis Olson and Charles Mossman, "Neural network forecasts of Canadian stock returns using accounting ratios," International Journal of Forecasting, Vol.19, No.3, pp.453-465, 2003

[12] Christopher Krauss, Xuan Anh Do and Nicolas Huck, "Deep neural networks, gradient-boosted trees, random forests: Statistical arbitrage on the S\&P 500," European Journal of Operational Research, Vol.259, No.2, pp.689-702, 2017

[13] Dixon Matthew, Klabjan Diego and Bang Jin Hoon, "Classification-based financial markets prediction using deep neural networks," Algorithmic Finance, Vol.6, No.3-4, pp.67-77, 2017 